\title{
Is early alcohol consumption related to adult alcohol use? Longitudinal analyses based on the Northern Sweden Cohort
}

\author{
Paul Delfabbro ${ }^{1}$ and Anne Hammarström ${ }^{2}$ \\ ${ }^{1}$ School of Psychology, University of Adelaide, South Australia \\ ${ }^{2}$ Department of Public Health and Clinical Medicine, Umeä University, Umeä, Sweden
}

\begin{abstract}
Aim: This paper examines whether early alcohol consumption is related to adult alcohol consumption and self-reported health.

Design: 1,083 people were tracked from the age of 16 years in 1981 to the age of 43 , with $94 \%$ of the living respondents $(n=$ 1,010) retained in the study.

Setting: Data were drawn from the Northern Swedish Cohort study.

Measures: Alcohol consumption at age 16 was the independent measure. Dependent measures included the level of alcohol consumption at age 43 years and self-reported health status. Socio-demographic control variables included parental relationship status, occupational status and employment, as well as the respondent's smoking status and level of social alienation.
\end{abstract}

Findings: Women who drank alcohol at greater amounts at age 16 were more likely to drink at a higher level at age 43 . No relationship was found between male consumption at age 16 and health or alcohol consumption at age 43. Alcohol consumption at age 16 was not significantly related to self-reported health at age 43 after other background variables had been controlled.

Conclusions: The results partially support previous research indicating an association between adolescent and longer-term adult drinking and health, but also highlight the importance of examining the role of socio-demographic factors as influential confounding variables.

Alcohol consumption during adolescence has long been recognised as a significant public health concern because of its potential impact on adolescent health and development and its association with antisocial behavior, delinquency and poorer educational outcomes (Jeffris, Power, \& Manor, 2005; McCambridge, McAlaney, \& Rowe, 2011; Viner \& Taylor, 2007). Although heavy alcohol consumption during this stage of life has often been depicted as part of a transitory phase of socially immature risk-taking and independence-seeking behavior, it has been increasingly noted that alcohol behaviors established during adolescence can have longer-term consequences. In addition to being associated with longer-term patterns of alcohol consumption, early alcohol consumption has been found to be associated with a number of poorer outcomes during early to mid-adulthood. Despite evidence of some discontinuity in individual patterns (Nordström \& Pape, 2012; Temple \& Filmore, 1986), it has generally been found that adolescents who drink at higher levels (see Ellickson, Tucker, \& Klein, 2003; Hammarström \& Janlert, 2002; Jeffris et al., 2005 for differing definitions) are more likely to drink at elevated levels in adulthood (Dubow,
Boxer, \& Huesmann, 2008; Huurre, Lintonen, Kaprio, Pelkonen, Marttunen, \& Aro, 2010; McCarty, Ebel, Garrison, DiGiuseppe, Christakis, \& Rivara, 2004; Merline, O’Malley, Schulenberg, Bachman, \& Johnson, 2004; Muthen \& Muthen, 2000; Rohde, Lewinsohn, Kahler, Seeley, \& Brown, 2001).

Early to mid-adolescent alcohol consumption can have a number of other longer-term consequences during adulthood. For example, in a detailed systematic review of over 50 longitudinal studies conducted by McCambridge et al. (2011) evidence points to a range of impacts. These include effects on hospital admissions and greater mortality (Andreasson, Romelsjo, \& Allebeck, 1991; Romelsjo \& Leifman, 1999); employment and psychological wellbeing (Locke \& Newcomb, 2003); mental health problems and drug dependence (Wells, Horwood, \& Fergusson, 2004); and smoking (Paavola, Vartianen, \& Haukkala, 2004).

As McCambridge et al. (2011) show, the exact parameters of the range of drinking behaviors which are influential, and the precise nature and timing of consequences, vary

Correspondence: Paul Delfabbro, Ph.D., School of Psychology, University of Adelaide, South Australia. Telephone: +61 8 8313 4936 , FAX: +61 88 313 3700; E-mail: Paul.delfabbro@adelaide.edu.au

Financial support: The study has been financed by The Swedish Research Council Formas dnr 259-2012-37

Keywords: alcohol consumption; health outcomes; middle adulthood; longitudinal 
across studies. There are several reasons for this. Not all studies use the same measures of alcohol consumption or the same follow-up periods. Alcohol consumption also tends to co-vary with a range of other variables, such as socio-economic status, employment status, and other substance use (Wennberg, Andersson, \& Bohman, 2002; Winefield, Tiggemann, Winefield, \& Goldney, 1993), so that the extent to which associations will be detected will also vary depending on the range of control or confounding variables that are taken into account. Even when associations are observed, it is not always possible to rule out other common antecedents. These may include differences in genetics or physiology, personality, and familial factors or other life experiences not adequately captured in many surveys. Nevertheless, despite these caveats, the effects observed in this area, across a range of studies, appear to be robust. They allow reasonable inferences to be drawn about the apparent association between elevated alcohol consumption during adolescence and adult outcomes.

The only significant limitation of much of this research is that outcomes have typically been tracked only into early adulthood. A 2011 review of longitudinal studies by McCambridge et al. found relatively few that examined outcomes into mid-adulthood (i.e., to 40 years of age and beyond). As well, a number of studies were confined to one gender or to special populations, and several experienced significant sample attrition. In larger studies that have examined long-term outcomes (e.g., Andreasson, Romelsjo, \& Allebeck, 1991; Romelsjo \& Leifman, 1999), much of the focus has been upon serious issues such as heart attacks, stroke, and premature death. Less attention has been directed towards the prevalence of general declines in health, which are likely to impose an ongoing burden on public health systems because of their impact on a larger proportion of the population.

In this study, we examined the stability of alcohol consumption and related general health consequences into mid-adulthood (age 43) in the Northern Swedish Cohort, which involves a 27-year tracking study with a 94\% retention rate. The study focuses on the physical and health consequences of early variations in alcohol consumption and examines gender differences. The principal hypotheses were that higher alcohol consumption at age 16 would be associated with (a) higher alcohol consumption at age 43, and (b) poorer self-reported health outcomes. These hypotheses were investigated after controlling for a number of confounding variables. These included measures of socio-economic status (SES), as several studies have found a link between lower SES and longer-term alcohol use (Anderson, Due, Holstein, \& Iverson, 2003; Due et al., 2011; Hammarstrom and Janlert, 2002; Janlert \& Hammarstrom, 1992; Wennberg et al., 2002); smoking (Viner \& Taylor, 2007); and parental relationships (Huure et al., 2010). The study also included two other measures less commonly included in longitudinal studies of alcohol—namely, the quality of meaningful spare time use and social alienation. Both of these variables have been found to be related to how people cope with misfortunes (e.g., unemployment) (see Winefield, Tiggemann,
Winefield, \& Goldney, 1993) and may therefore be related to the likelihood of people using alcohol more heavily.

\section{Method}

\section{Participants}

The data for this paper were drawn from the Northern Swedish Cohort (see Hammarström \& Janlert, 2012 for a detailed summary of sampling procedures). This study commenced in 1981 and involved a survey of 1,083 young people in their final compulsory year of schooling (age 16), drawn from all nine schools in the town of Luleå. The cohort has been confirmed in previous analyses to be representative of the country as a whole with regard to both socio-demographic characteristics and self-reported health status (Hammarström \& Janlert, 2012). This sample has been resurveyed four times (at ages 18, 21, 30, and 43). At the 27-year follow-up conducted in $2008,94.3 \%$ of the original sample of living participants were still participating in the study and providing survey and other data. The analytical sample for this paper comprised $n=1,010$ individuals $(M=522, F=488)$ with a mean age of 43 . In this paper, we utilise data drawn from the first (age 16) and most recent (age 43) data collection waves, because of the interest in the consequences of adolescent behavior on longer-term adult health.

\section{Measures}

Outcome variables (age 43)

(a) Alcohol consumption. Alcohol consumption was based on separate measures of the frequency and per-occasion volume of beer, wine and spirits consumed. A total consumption of pure alcohol was calculated by assigning ethanol percentages of $4.5 \%$ to beer, $10 \%$ to wine and $40 \%$ to spirits. These figures were combined to obtain the total estimated centiliters consumed per year (summarized for males and females in Table 1). The distribution for this variable was highly positively skewed, so a log transformation was applied, and this yielded a normal distribution of values that was suitable for use in parametric analyses. All analyses involving alcohol were therefore based on the log.centiliter values for age 43 .

(b) Self-rated health. Respondents were asked to rate whether their physical health was generally good or bad (0 = "bad," 1 = "neither good nor bad," and 2 = "good"). This variable was binary recoded, so that $0=$ "bad or "neither good nor bad" and 1 = "good."

\section{Independent variables (age 16)}

(a) Alcohol consumption. This variable was calculated using the same method as consumption at age 43 .

(b) Parental unemployment. A single item captured adolescent reports of whether either of their parents had been unemployed in the previous 12 months: $0=$ "no," $1=$ "yes."

(c) Parental Occupational class. Occupational classifications were based on the Swedish classification system of social groups (Johansson, 1970) in use until the 
1980s: Social group 1 (including entrepreneurs and higher white-collar workers), social group 2 (including lower white-collar workers), and social group 3 (including manual and non-manual workers). In our study, people included in social group 3 were classified as having working-class occupations. As a result of very high correlations between the classifications determined for mothers and fathers, these two variables were combined to indicate the number of parents who could be classified as having a working-class profession, where $0=$ "no workingclass parents," 1 = "one working-class parent" and 2 = "two working-class parents.”

(d) Parental relationship quality. Adolescents were asked to rate the quality of their relationship with each of their parents on a five-point scale ranging from 1 = "very good" to 5 = "very poor." Separate variables were available for mother and father, which we identified as "relationship with dad" and "relationship with mum."

(e) Parental divorce or separation. Adolescents indicated whether their parents were divorced or separated, where $0=$ "parents married" and 1 = "parents divorced."

(f) Smoking. A variable was used to capture whether respondents smoked cigarettes daily ( $0=$ "no,” 1 = “yes”).

(g) Social Alienation. The Srole Anomie scale is an eightitem measure that asks participants to respond to a series of statements on four-point rating scales, where agreement is indicated by higher scores. Total scores range from eight to 32 , where higher scores indicate greater anomie or disillusionment. The eight statements, translated back from Swedish, were:

- This is not a good time to have children, given the state of the world.

- Most people do not care what happens to others.

- I feel detached from what happens around me.

- I find myself asking whether life is worth living.

- Even though some doubt it, things are worse and worse for Swedes.

- Nowadays, I find it pointless to try my best.

- Nowadays, the only thing that is important is to make money, in any way possible.

- Nowadays, you should live for today and not care about tomorrow.

(h) Use of spare time. Respondents indicated on a fivepoint scale the extent to which they make meaningful use of their spare time, where 1 = "very meaningful," 2 = "a bit meaningful," 3 = "either/or," $4=$ "not especially meaningful,” 5 = "not at all meaningful.”

\section{Data Analytical Strategy}

The principal focus of analyses was to examine whether higher alcohol consumption at age 16 predicted outcomes at age 43. The principal outcome variables were alcohol consumption level and self-reported health. A number of control or confounding variables were considered, including parental divorce; quality of the respondent's relationship with parents (mother and father); parental unemployment; social alienation scores; quality of meaningful spare time use; and smoking status. Hierarchical linear regression was used to model the best predictors of alcohol consumption at age 43 . All of the control variables were added on Step 1 and log.centiliters of alcohol consumption at age 16 was entered on the second step. For self-reported health at age 43 years $(0=$ "not good," 1 = "good”), logistic regression was used with a similar ordering of variable entry.

\section{Results}

Table 1 summarizes the descriptive characteristics of the sample in relation to the outcome variables and confounding variables. As indicated, at age 16, girls were more likely to report smoking than boys, and around one in five reported parental unemployment. Both genders reported having consumed a similar amount of alcohol at the age of 16, but males reported over a fourfold increase in consumption from the age of 16 to 43 . By the age of 43 , men reported drinking more than twice as much per year as women. Most of the sample reported good health at age 43 , and scored in the middle range for leisure time usage and social alienation. Girls at age 16 generally reported having poorer relationships with their fathers than did boys. In summary, the samples of men and women were generally very well matched on relevant background variables.

The bivariate relationship between log.alcohol consumption at age 16 and age 43 was small, but significant for males $(r$ $=.18, p<.05)$ and females $(r=.17, p<.05)$. Table 2 summarizes the relationship between alcohol consumption at age 16 and at age 43. After controlling for the confounding variables, the results showed a positive association for women. For men, greater consumption at age 43 was associated with having been more alienated at age 16 and with having parents who were separated or divorced. For women, having parents with a working-class status was associated with reduced consumption at age 43 .

The associations between alcohol consumption and selfreported health were generally in the expected direction. For example, those who had poorer health at age 43 drank more at age $43(M=558.1, S D=1871.9)$ than those with good health $(M=307.2, S D=436.3), t(994)=2.48, p<$ .05. However, the predicted association between drinking at age 16 and health at age 43 was not found to be significant, although there was a trend towards greater drinking in those who reported lower health at age $16(M=$ $170.5, S D=355.7$ centiliters) as opposed to those who gave lower health ratings at age $43(M=127.3, S D=390.0), t$ $(988)=1.72, p<.10$. However, as Table 3 shows, there was very little relationship between higher alcohol consumption at age 16 and self-reported health at age 43 for men or women, once other variables had been controlled. In fact, for women there were no significant predictors at all. For men, poorer self-reported health at age 43 was associated with high social alienation scores at the age of 16 . 
Table 1

Sample descriptives

\begin{tabular}{|c|c|c|c|}
\hline & $\begin{array}{c}\text { Males } \\
N=511 \\
N(\%)\end{array}$ & $\begin{array}{c}\text { Females } \\
N=482 \\
N(\%)\end{array}$ & $X^{2}(1)$ \\
\hline Smoker (age 16) & $88(17.2)$ & $155(32.4)$ & $31.0^{* * *}$ \\
\hline Parental unemployment (age 16) & $97(19.8)$ & $84(18.0)$ & $<1$ \\
\hline Parental divorce & $97(19.3)$ & $84(18.1)$ & $<1$ \\
\hline \multirow[t]{2}{*}{ Good health (age 43) } & $333(65.2)$ & $304(63.1)$ & $<1$ \\
\hline & $M(S D)$ & $M(S D)$ & $t$-value \\
\hline Dad relationship & $1.7(.99)$ & $2.0(1.09)$ & $4.75^{* * *}$ \\
\hline Mum relationship & $1.4(.65)$ & $1.5(.73)$ & 1.57 \\
\hline Social alienation (age 16) & $17.9(3.62)$ & $18.6(3.42)$ & $2.80^{* *}$ \\
\hline Alcohol (centilitres per annum at age 16) & 155.7 (426.39) & $131.2(327.92)$ & $<1$ \\
\hline Alcohol (centilitres per annum at age 43) & $569.7(1514.20)$ & $210.1(589.71)$ & $4.88 * * *$ \\
\hline Meaningful leisure time use (age 16) & $2.2(1.08)$ & $2.2(0.93)$ & $<1$ \\
\hline
\end{tabular}

${ }^{* *} p<.01,{ }^{* * *} p<.001$

Table 2

Multiple regression analyses of consumption of alcohol at age 43, based on age 16 predictors

\begin{tabular}{|c|c|c|c|c|c|c|}
\hline & \multicolumn{3}{|c|}{ Model 1} & \multicolumn{3}{|c|}{ Model 2} \\
\hline & $B$ & Beta & $t$ & $B$ & Beta & $t$ \\
\hline \multicolumn{7}{|l|}{ Men } \\
\hline Constant & 2.19 & & & 2.23 & & \\
\hline Social class & -.03 & -.05 & $<1$ & -.03 & -.05 & $<1$ \\
\hline Family unemployment & .03 & .06 & $<1$ & .03 & .06 & $<1$ \\
\hline Divorce & .15 & .12 & $2.00 *$ & .16 & .13 & $2.04 *$ \\
\hline Dad relationship & .02 & .04 & $<1$ & .02 & .04 & $<1$ \\
\hline Mum relationship & .04 & .05 & $<1$ & .04 & .05 & $<1$ \\
\hline Smoked daily & .08 & .07 & 1.16 & .09 & .08 & 1.20 \\
\hline Meaningful leisure time & -.03 & -.07 & 1.16 & -.03 & -.07 & 1.23 \\
\hline Anomie & .01 & .14 & $2.23 *$ & .01 & .14 & $2.25^{*}$ \\
\hline Alcohol age 16 & & & & -.02 & -.03 & $<1$ \\
\hline Adj-R ${ }^{2}$ & & & .03 & & & .03 \\
\hline$\Delta \mathrm{Adj}-\mathrm{R}^{2}$ & & & & & & .00 \\
\hline F-value & & & $2.13^{*}$ & & & 1.91 \\
\hline \multicolumn{7}{|l|}{ Women } \\
\hline Constant & 2.00 & & & 1.83 & & \\
\hline Social class & -.09 & -.13 & $2.11^{*}$ & -.10 & -.15 & $2.35^{*}$ \\
\hline Family unemployment & -.01 & -.01 & $<1$ & -.01 & -.01 & $<1$ \\
\hline Divorce & -.01 & -.01 & $<1$ & -.04 & -.03 & $<1$ \\
\hline Dad relationship & .06 & .12 & 1.75 & .05 & .09 & $<1$ \\
\hline Mum relationship & .01 & .01 & $<1$ & -.01 & -.02 & 1.61 \\
\hline Smoked daily & -.01 & -.01 & $<1$ & -.12 & -.12 & $<1$ \\
\hline Meaningful leisure time & .05 & .08 & 1.33 & .03 & .06 & $<1$ \\
\hline Anomie & -.01 & -.03 & $<1$ & -.01 & -.03 & $<1$ \\
\hline Alcohol age 16 & & & & .19 & .22 & $3.11^{* *}$ \\
\hline Adj- $R^{2}$ & & & .01 & & & .02 \\
\hline$\Delta \operatorname{Adj}-R^{2}$ & & & & & & .01 \\
\hline F-value & & & $<1$ & & & 1.80 \\
\hline
\end{tabular}

${ }^{*} p<.05 * * p<.01$ 
Table 3

Logistic regression analyses of poor self-rated health at age 43, based on age 16 predictors

\begin{tabular}{|c|c|c|c|c|c|c|}
\hline & \multicolumn{3}{|c|}{ Model 1} & \multicolumn{3}{|c|}{ Model 2} \\
\hline & $\boldsymbol{B}$ & Wald & OR & $B$ & Wald & OR \\
\hline \multicolumn{7}{|l|}{ Men } \\
\hline Constant & 2.58 & & & 2.98 & & \\
\hline Family unemployment & -.09 & $<1$ & $.92(.70-1.20)$ & -.08 & $<1$ & $.92(.70-1.20)$ \\
\hline Divorce & .17 & $<1$ & $1.19(.64-2.20)$ & .23 & $<1$ & $1.26(.68-2.35)$ \\
\hline Dad relationship & -.22 & 2.54 & $0.8(.61-1.05)$ & -.21 & 2.33 & $.81(.62-1.07)$ \\
\hline Mum relationship & .13 & $<1$ & $1.14(.76-1.71)$ & .13 & $<1$ & $1.14(.76-1.72)$ \\
\hline Smoked daily & -.41 & 1.93 & $.67(.37-1.18)$ & -.29 & $<1$ & $.75(.41-1.37)$ \\
\hline Meaningful leisure time & .08 & $<1$ & $1.08(.86-1.36)$ & .08 & $<1$ & $1.08(.86-1.36)$ \\
\hline Anomie & -.10 & $6.68^{*}$ & $.91(.85-.98)$ & -.09 & $5.80 *$ & $.91(.85-.98)$ \\
\hline Alcohol age 16 & & & & -.29 & 1.39 & $.75(.46-1.22)$ \\
\hline$-2 L L R$ & & & 354.5 & & & 353.2 \\
\hline \multicolumn{7}{|l|}{ Women } \\
\hline Constant & 1.82 & & & 1.98 & & \\
\hline Family unemployment & .15 & $<1$ & $1.16(.75-1.80)$ & .15 & $<1$ & $1.16(.75-1.80)$ \\
\hline Divorce & -.02 & $<1$ & $.98(.54-1.77)$ & .004 & $<1$ & $1.00(.55-1.83)$ \\
\hline Dad relationship & -.20 & 2.37 & $.82(.64-1.06)$ & -.19 & 2.14 & $.83(.64-1.07)$ \\
\hline Mum relationship & -.06 & $<1$ & $.94(.68-1.30)$ & -.05 & $<1$ & $.95(.69-1.33)$ \\
\hline Smoked daily & .15 & $<1$ & $1.16(.69-1.93)$ & .25 & $<1$ & $1.28(.72-2.29)$ \\
\hline Meaningful leisure time & -.17 & 1.55 & $.85(.65-1.10)$ & -.16 & 1.34 & $.85(.65-1.12)$ \\
\hline Anomie & -.04 & $<1$ & $.97(.89-1.05)$ & -.03 & $<1$ & $.97(.89-1.05)$ \\
\hline Alcohol age 16 & & & & -.17 & $<1$ & $.84(.54-1.32)$ \\
\hline$-2 \mathrm{LLR}$ & & & 375.7 & & & 375.11 \\
\hline
\end{tabular}

Note: The models for women revealed no significant predictors. Health is coded $(0=$ not good, $1=$ good $)$. Higher scores on this variable $=$ more negative relationship = lower probability of being in the good health group. ${ }^{*} p<.05$

\section{Discussion}

The findings from this study provided only partial support for the principal hypotheses. Although higher alcohol consumption during adolescence was found to be associated with higher consumption during middle adulthood for women, a similar relationship was not observed for men. Consistent with the findings of other longer-term cohort studies (e.g., Viner \& Taylor, 2007), the findings for women suggest that patterns of alcohol consumption in adolescence appear to be related to subsequent behavior. By contrast, the results observed for males, although inconsistent with predictions, are more consistent with the broad observations of Temple et al. (1986) and Nordström and Paper (2011), both of whom have drawn attention to the difficulties associated with predicting longer-term trajectories of alcohol consumption, as well as the decreasing ability of statistical models to predict outcomes over a longer period. In this study, it was observed that males and females were generally matched in terms of their mean alcohol consumption at the age of 16 , but that there was a significant divergence in consumption by the age of 43 . Men reported over a four-fold increase in alcohol consumption, whereas women reported only a modest increase. Discontinuity in alcohol consumption from adolescence to adulthood may, therefore, be a greater phenomenon among the males in this sample, and this is an issue worth of further investigation.

Alcohol consumption was not related to self-reported health at age 43 once other variables had been controlled. Thus, while other studies have shown that alcohol use is associated with long-term health consequences, our results suggest that these associations appear to be more strongly related to other co-occurring factors. Such observations again reflect Viner and Taylor's (2007) observations that the apparent clustering of general substance use and healthrelated outcomes may make the separate statistical contributions of alcohol consumption to health outcomes more difficult to discern. These findings suggest the policy importance of considering early alcohol consumption as a risk factor for subsequent alcohol-related behavior, although it is unclear from our results whether consumption levels at age 16 are necessarily indicative of long-term health outcomes. As Wennberg et al. (2002) has shown, it may be that greater insights into the effects of alcohol can be discerned by looking more carefully at the patterns of alcohol consumption beyond age 16. Many people who drink at age 16 do not continue to drink at the same level beyond this age, although there are likely to be some who maintain consistently high levels of consumption over time. Accordingly, one way in which these findings could be extended is to examine the patterns of consumption over time, taking into account data obtained at measurement 
points collected between the ages of 16 and 43 (e.g., at ages 21 and 28). Such analyses may have the capacity to identify differences in longer-term exposure to alcohol and allow clearer insights into its effects on subsequent health.

\section{Study strengths and limitations}

One strength of this study is that conclusions are based upon a substantial follow-up period, which is commensurate with some of the longest tracking periods documented in the recent review by McCambridge et al. (2011). Another strength is the extremely high participation rate over time, which is of crucial importance, as earlier research has shown that study non-responders tend to have higher alcohol consumption than responders (Novo, Hammarström, \& Janlert, 1999). The analyses also control for important confounding variables known to have an association with alcohol consumption; these encompass both socio-demographic factors and health-related correlates such as smoking.

Despite these strengths, a number of methodological and conceptual caveats should be noted. The first is that the sample was drawn from Sweden and at a particular point in history, so not all of the findings can necessarily be generalised to other countries. Countries differ in their drinking regulations and this may influence consumption rates over time. Second, the use of self-report methods means that the responses may not have necessarily reflected actual behavior. A third issue is that this study focused on general levels of alcohol consumption, rather than binge drinking or heavy regular drinking per se, which may have reduced the magnitude of potential effect sizes. In some other studies (e.g.., Hurrare et al., 2010), the higher-risk group was defined as those who engaged in excessive alcohol use; others (e.g., Norström \& Pape, 2012; Viner \& Taylor, 2007) have compared binge drinkers to those with other consumption patterns.

Finally, care should be taken to avoid making unwarranted inferences of causation based on the associations reported in this paper. Although the study used a longitudinal design, the results do not necessarily show that earlier alcohol consumption is causally related to consumption later in life or to subsequent health outcomes. There may be underlying common or third variables (e.g., genetic, dispositional or other socio-demographic factors) that explain the relationship between the variables of interest in this paper.

\section{Conclusion}

Notwithstanding these potential limitations, this study provides some additional, although qualified, support for previous studies. The results highlight the importance of maintaining vigilance over the behavior of mid-teens. Whether a symptom of other factors or problematic in its own right, early adolescent drinking appears to be an indicator that can be used to anticipate future alcohol consumption in women. From a public policy and educational perspective, the results support the value of alcohol-related regulatory and educational strategies that limit adolescent access to alcohol and that draw attention to the potential consequences of higher levels of consumption at a younger age.

\section{References}

Anderson, A., Due, P., Holstein, B. E., \& Iverson, L. (2003). Tracking drinking behaviour from age 15-19 years. Addiction, 98, 1505-1511.

Andreasson, S., Romelsjo, A., \& Allebeck, P. (1991). Alcohol, social factors and mortality among young men. British Journal of Addiction, 86, 877-887. doi:10.1111/j.1360-0443.1991.tb01843.x

Dubow, E. F., Boxer, P., \& Huesmann, L. R. (2008). Childhood and adolescent predictors of early and middle adulthood alcohol use and problem drinking: The Columbia County Longitudinal Study. Addiction, 103, 36-47. doi:10.1111/j.1360-0443.2008.02175.x

Due, P., Krolner, R., Rasmussen, M., Anderson, A., Trab Damsgaard, M., Graham, H., \& Holstein, B. E. (2011). Pathways and mechanisms in adolescence contribute to adult health inequalities. Scandinavian Journal of Public Health, 39, 62-78. doi:10.1177/1403494810395989.

Ellickson, P. L., Tucker, J. S., \& Klein, D. J. (2003). Tenyear prospective study of public health problems associated with early drinking. Pediatrics, 111, 949955. doi:10.1542/peds.111.5.949

Hammarström, A., \& Janlert, U. (2002). Early unemployment can contribute to adult health problems: Results from a longitudinal study of school leavers. Journal of Epidemiology and Community Mental Health, 56, 624-630. doi:10.1136/jech.56.8.624

Hammarström, A., \& Janlert, U. (2012). Cohort profile: The Northern Swedish Cohort. International Journal of Epidemiology, 14, 1545-1552. doi:10.1093/ije/dyr118

Huurre, T, Lintonen, T., Kaprio, J., Pelkonen, M., Marttunen, M., \& Aro, H. (2010). Adolescent risk factors for excessive alcohol use at age 32 years: A 16-year prospective study. Social Psychiatry and Epidemiology, 45, 125-134. doi:10.1007/s00127-0090048-y

Janlert, U., \& Hammarström, A. (1992). Alcohol consumption among unemployed youths: Results from a prospective study. British Journal of Addiction, 87, 703-714. doi:10.1111/j.1360-0443.1992.tb02716.x

Jeffris, B. J. M. H., \& Power, C., \& Manor, O. (2005). Adolescent drinking level and adult binge drinking in a national birth cohort. Addiction, 100, 543-549. doi:10.1111/j.1360-0443.2005.01034.x

Johansson, S. (1970). The adult population's state of health. Stockholm, Sweden: Fritzes [in Swedish].

Locke, T., \& Newcomb, M. D. (2003). Psychosocial outcomes of alcohol involvement and dysphoria in women: A 16-year prospective community study. Journal of the Study of Alcohol and Drugs, 64, 531546.

McCambridge, J., McAlaney, J., \& Rowe, R. (2011). Adult consequences of late adolescent alcohol consumption: 
A systematic review of cohort studies. Plos Medicine, 8, 1-13. doi:10.1371/journal.pmed.1000413

McCarty, C. A., Ebel, B. E., Garrison, M. M., DiGiuseppe, D. L., Christakis, D. A., \& Rivara, F. P (2004). Continuity of binge and harmful drinking from late adolescence to early adulthood. Pediatrics, 114, 714719. doi:10.1542/peds.2003-0864-L

Merline, A. C., O’Malley, P. M., Schulenberg, J. E., Bachman, J. G., \& Johnson, L. D. (2004). Substance use among adults 35 years of age: Prevalence, adulthood predictors, and impact of adolescent substance abuse. American Journal of Public Health, 94, 96-102. doi:10.2105/AJPH.94.1.96

Muthen, B. O., \& Muthen, L. K. (2000). The development of heavy drinking and alcohol-related problems from ages 18 to 37 in a U.S. national sample. Journal of Studies on Alcohol, 61, 290-300.

Norström, T., \& Pape, H. (2012). Associations between adolescent heavy drinking and problem drinking in early adulthood: Implications for prevention. Journal of Studies on Alcohol and Drugs, 73, 542-548.

Novo, M., Hammarström, A., \& Janlert, U. (1999). Does low willingness to respond introduce a bias? Results from a socio-epidemiological study among young men and women. International Journal of Social Welfare, 8, 155-163. doi:10.1111/1468-2397.00076

Paavola, M., Vartianen, E., \& Haukkala, A. (2004). Smoking, alcohol use, and physical activity: A 13-year longitudinal study ranging from adolescence into adulthood. Journal of Adolescent Health, 35, 238-244. doi:10.1016/j.jadohealth.2003.12.004

Rohde, P., Lewinsohn, P.M., Kahler, K. W., Seeley, J. R., \& Brown, R. A. (2001). Natural course of alcohol use disorders from adolescence to young adulthood. Journal of the American Academy of Child and Adolescent Psychiatry, 40, 83-90. doi:10.1097/00004583-200106000-00017

Romelsjo, A., \& Leifman, A. (1999). Association between alcohol consumption and mortality, myocardial infarction, and stroke in 25-year follow-up of 49,618 young Swedish men. British Medical Journal, 319, 821-822. doi:10.1136/bmj.319.7213.821

Temple, M. T., \& Filmore, K. M. (1986). The variability of drinking patterns and problems among young men, age 16-31: A longitudinal study. The International Journal of the Addictions, 20, 1595-1620.

Viner, R. M., \& Taylor, B. (2007). Adult outcomes of binge drinking in adolescence: Findings from a UK national birth cohort. Journal of Epidemiology and Community Health, 61, 902-907. doi:10.1136/jech.2005.038117

Wells, J. E., Horwood, I. J., \& Fergusson, D. M. (2004). Drinking patterns in mid-adolescence and psychosocial outcomes in late adolescence and early adulthood. Addiction, 99, 1529-1541. doi:10.1111/j.1360-0443.2004.00918.x

Wennberg, P., Andersson, T., \& Bohman, M. (2002). Psychosocial characteristics at age 10; differentiating between adult alcohol use pathways: A prospective longitudinal study. Addictive Behaviors, 27, 115-130.
Winefield, A. H., Tiggemann, M., Winefield, H. R., \& Goldney, R. (1993). Growing up with unemployment. London, UK: Routledge. 